\title{
Perancangan Sistem Start Engine Mobil Menggunakan Fingerprint
}

\author{
Dicky Dharmawan ${ }^{1}$, Joni Fat ${ }^{1}$, Dali Santun Naga ${ }^{2}$
}

\begin{abstract}
The advancement in automotive technology triggers a lot of innovations. This design which based on fingerprint technology is one of the newest innovations to catch up with the newest technology. This system could verify he auto-mobile owner and authorize people in order to use the automobile. On the other hand, this system has a a higher security mode than others. Our design could be considered as a new innovation from an older system with an additional security system. Our innovation is to modify and join up immobilizer system to start-top engine system and fingerprint system. We innovate by utilizing fingerprint technology and microcontroller. This system uses fingerprint sensor which is connected to microcontroller. Microcontroller is used to save owner's fingerprint. If the saved data matches to an input, microcontroller will send a signal to activate a relay. The relay is used to start the automobile engine. If the input doesn't match with the saved data, the system will try for three times before activating an alarm. The alarm will sound for thirty seconds. We hope that automobile owner could have a beneficial from our design. We conclude that our high security design could bring an indifference to other system.
\end{abstract}

Keywords: automotive innovation, start engine, car, fingerprint, security system

\begin{abstract}
ABSTRAK: Perkembangan teknologi dalam dunia otomotif yang sangat pesat memicu banyak munculnya ide-ide baru yang inovatif. Sistem start engine mobil dengan menggunakan fingerprint ini merupakan inovasi terbaru untuk mengikuti perkembangan dan kemajuan teknologi. Sistem ini dapat mengetahui siapa pemilik mobil dan siapa saja yang dapat menggunakan mobil, di sisi lain sistem ini memiliki sistem keamanan yang sangat tinggi dibandingkan sistem yang sudah ada pada kendaraan. Sistem ini merupakan inovasi dari sistem yang sudah ada pada kendaraan. Sistem yang sudah ada pada kendaraan belum dilengkapi sistem keamanan. Dari kekurangan sistem yang sudah ada muncul ide yang inovatif untuk melengkapi sistem yang sudah ada dengan menambahkan sistem keamanan. Inovasi yang muncul yaitu dengan memodifikasi dan menggabungkan sistem immobilizer dan sistem start-stop engine dengan menggunakan sensor fingerprint. Inovasi untuk memodifikasi sistem tersebut dirancang dengan memanfaatkan teknologi fingerprint dan mikrokontroler. Sistem ini menggunakan sensor sidik jari yang terhubung dengan mikrokontroler. Mikrokontroler digunakan untuk menyimpan data sidik jari pemilik mobil. Bila sidik jari yang dimasukkan sesuai dengan data yang tersimpan maka mikrokontroler akan mengirim sinyal untuk mengaktifkan relay. Relay digunakan untuk menghidupkan mesin mobil. Pada saat sidik jari yang dimasukkan tidak dikenali oleh sensor sidik jari sebanyak tiga kali maka mikrokontroler akan mengirim sinyal untuk mengaktifkan alarm selama tiga puluh detik. Dengan adanya sistem start engine mobil menggunakan fingerprint, pengguna mendapat kemudahan. Selain itu, juga memberikan tingkat keamanan yang lebih dibandingkan sistem yang sudah ada.
\end{abstract}

Kata kunci : inovasi otomotif, start engine, mobil, fingerprint, sistem keamanan.

\section{PENDAHULUAN}

$\mathrm{T}$ eknologi dan inovasi pada saat ini sangat berkembang pesat. Hal ini terlihat dari banyaknya sistem yang berubah dari sistem konvensional menjadi sistem yang otomatis. Perkembangan teknologi dan inovasi juga sudah mulai merambat pada dunia otomotif. Perkembangan teknologi dan inovasi yang terjadi pada dunia otomotif memang sedikit banyak sangat membantu penggunanya. Sistem konvensional pada mobil sedikit banyak sudah mulai digantikan dengan menggunakan sistem yang otomatis. Salah satu contohnya adalah sistem konvensioanal untuk menghidupkan mesin mobil sudah mulai ditinggalkan pada kendaraan keluaran terbaru.

Pada sistem konvensional untuk menghidupkan mesin mobil yaitu dengan cara, pengguna memasukkan anak kunci kendaraannya ke rumah kunci pada kendaraan. Kunci tersebut dapat digeser ke posisi accu untuk melepaskan kemudi kendaraan dari kunci stang. Pengguna dapat menggeser kunci tersebut ke posisi on kemudian digeser seketika ke posisi start untuk menghidupkan mesin kendaraan. Cara seperti ini sudah tidak digunakan lagi pada kendaraan keluaran terbaru. Beberapa teknologi dan inovasi yang hadir pada produk otomotif seperti mobil tidak hanya memberikan kesan mewah, melainkan juga memberikan keamanan pada kendaraan dan memudahkan penggunanya. Salah satu bentuk dari inovasi dan teknologi di dunia otomotif pada mobil yaitu penambahan kamera parkir mundur, sensor parkir mundur, smart cross connect, immobilizer, start-stop engine serta yang terbaru ini akan hadir kamera spion atau spion tanpa kaca dan smart key [1].

Perkembangan inovasi dan teknologi pada dunia otomotif umumnya ada pada kendaraan terbaru saja. Hal ini dikarenakan perusahaan mobil selalu berusaha mengembangkan dan memberikan layanan terbaru untuk memberikan kemudahan dan keamanan para penggunanya. Awalnya sistem konvensional untuk menghidupkan mesin mobil dikembangkan menjadi fitur immobilizer. Fitur immobilizer yang sudah ada dikembangkan kembali menjadi fitur terbaru yaitu start-stop engine[2].

Pada tahun ini, produsen mobil sedang mengembangkan kembali fitur start-stop engine menjadi fitur smart key. Smart key merupakan fitur keamanan pada kendaraan mobil. Smart key adalah fitur yang digunakan pada mobil untuk membuka kunci pintu mobil secara otomatis dengan menggunakan sidik jari [3]. Namun sayangnya fitur ini dikembangkan hanya untuk membuka kunci pintu mobil saja. Fitur ini belum dikembangkan untuk menghidupkan mesin mobil menggunakan sidik jari dan selain itu, fitur ini belum hadir di Indonesia. Tampilan fisik dari fitur smart key dapat dilihat pada Gambar 1.

Pada saat, ini kendaraan terbaru sudah tidak menggunakan anak kunci lagi untuk menghidupkan mesin kendaraannya melainkan hanya menggunakan tombol start-stop engine dan dikombinasikan dengan remote

\footnotetext{
${ }^{1}$ Program Studi Teknik Elektro, Fakultas Teknik, Universitas Tarumanagara

2 Prgram Studi Teknik Informatika Fakultas Sistem Informasi, Universitas Tarumanagara
} 
control mobil yang harus ada di dalam kendaraan [2]. Sistem seperti ini sangat memudahkan pengguna untuk menghidupkan dan mematikan mesin kendaraannya secara otomatis, namun sistem ini kurang dibekali dengan sistem keamanan. Pada saat pengguna kehilangan atau lupa menyimpan remote control kendaraannya maka mesin kendaraan tersebut dapat dihidupkan dengan mudah. Sistem keamanan pada mobil juga merupakan salah satu hal yang penting bagi para pemilik mobil.

Sistem keamanan merupakan sistem yang sangat dibutuhkan oleh para pemilik mobil. Melihat sistem yang sudah ada belum dilengkapi dengan sistem keamanan, maka muncul inovasi untuk memodifikasi dan merancang sistem untuk melengkapi kekurangan sistem yang sudah ada. Inovasi yang muncul untuk memodifikasi sistem tersebut yaitu membuat sistem otomatis start engine menggunakan fingerprint dan memiliki alarm sebagai indikator sistem keamanan pada kendaraan.

Sistem start engine menggunakan fingerprint merupakan sistem keamanan kendaraan pada saat pengguna ingin menghidupkan mesin mobil secara otomatis. Sistem start engine menggunakan fingerprint ini dapat digunakan untuk menghidupkan mesin kendaraan secara otomatis dengan menggunakan sidik jari pengguna yang sudah terdaftar. Inovasi ini muncul untuk melengkapi kekuranganpada fitur yang sudah ada. Inovasi untuk memodifikasi sistem tersebut dirancang dengan memanfaatkan teknologi sensor fingerprint dan mikrokontroler.

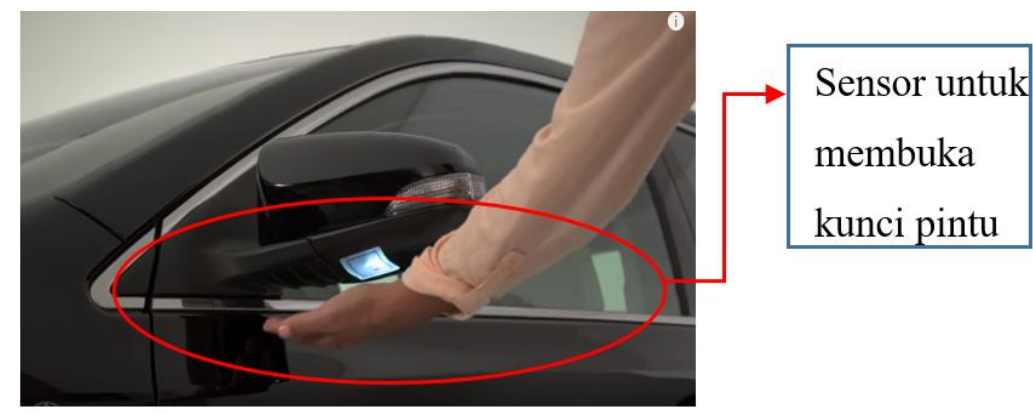

- Gambar 1. Tampilan Fisik Fitur Smart Key

Sensor fingerprint pada sistem ini digunakan sebagai modul pendeteksi yang berfungsi untuk membaca sidik jari pengguna kendaraan sedangkan, mikrokontroler Arduino digunakan sebagai modul pemroses pada sistem yang dirancang. Selain itu, modul pemroses juga berfungsi untuk menyimpan data sidik jari pengguna yang didaftarkan dan digunakan sebagai sistem keamanan pada kendaraan. Modul pemroses dapat mengenali sidik jari pengguna yang dapat menghidupkan mesin mobil secara otomatis bila sidik jari pengguna yang digunakan sudah didaftarkan dan berhasil disimpan. Pada saat sidik jari pengguna yang digunakan tidak terdaftar maka, modul pemroses tidak dapat menghidupkan mesin mobil secara otomatis.

Sistem ini dirancang agar dapat menghidupkan mesin mobil secara otomatis hanya dengan menggunakan sidik jari pengguna yang sudah didaftarkan dan dilengkapi alarm sebagai indikator keamanan. Dengan adanya sistem ini pengguna tidak perlu khawatir akan mesin kendaraannya dapat dihidupkan dengan mudah oleh siapapun, karena mesin mobil hanya dapat dihidupkan dengan menggunakan sidik jari pengguna yang sudah terdaftar saja. Mesin tidak dapat dihidupkan bila sidik jari belum didaftarkan atau sidik jari tidak dikenal dan sistem akan menghidupkan alarm bila ada pengguna lain yang tidak dikenal ingin mencoba menghidupkan mesin kendaraan tersebut.

\section{METODOLOGI PENELITIAN}

Alat yang dirancang dapat digunakan untuk menghidupkan mesin mobil secara otomatis dengan menggunakan sidik jari. Selain itu alat ini juga berfungsi sebagai sistem keamanan pada mobil karena mesin hanya dapat dihidupkan dengan menggunakan sidik jari pengguna yang sudah didaftarkan saja. Alat ini juga dilengkapi dengan adanya alarm sebagai indikator bila ada pengguna yang tidak dikenal mencoba menghidupkan mesin. Alat ini kemudian diletakkan dan dipasang di dalam dasboard mobil sehingga mobil dapat mendeteksi dan mengenali pengguna mobil. Pengguna dapat menggunakan sidik jari yang sudah didaftarkan terlebih dahulu untuk menghidupkan mesin kendaraanya.

Alat yang dirancang ini menggunakan modul pendeteksi sidik jari dan modul pemroses. Selain itu, untuk mendukung alat yang dirancang maka dibuatlah modul registrasi, modul otomatis starter, dan modul program security. Pada modul pendeteksi sidik jari digunakan untuk membaca dan mengambil data sidik jari pengguna yang ingin didaftarkan. Sedangkan pada modul pemroses digunakan untuk tempat menyimpan data sidik jari pengguna yang didaftarkan sekaligus sebagai pemroses pada sistem ini.

Modul registrasi digunakan untuk mendaftarkan dan menyimpan sidik jari pengguna ke dalam sistem. Pada modul otomatis starter digunakan untuk menghidupkan mesin mobil secara otomatis sehingga dapat memudahkan pengguna dalam menghidupkan mesin mobil. Pada modul program security digunakan untuk mengatur dan mengontrol seluruh sistem. 
Modul program security juga sekaligus sebagai sistem keamanan pada mobil. Modul program security ini dapat mengenali sidik jari pengguna yang dapat menghidupkan mesin mobil dan mengenali sidik jari pengguna yang tidak dapat menghidupkan mesin mobil. Selain itu, modul program security dapat mengaktifkan modul otomatis starter sehingga mesin dapat dihidupkan secara otomatis dan dapat mengaktifkan alarm bila ada pengguna yang tidak dikenal ingin mencoba menghidupkan mesin mobil.

Tahap-tahap penyusunan perancangan sistem start engine mobil menggunakan fingerprint ini memiliki diagram blok yang dapat dilihat pada Gambar 2.

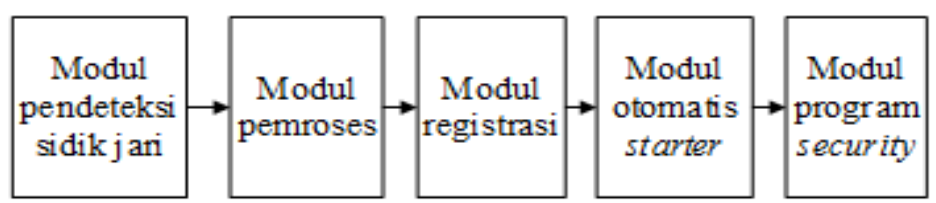

- Gambar 2. Diagram Blok Tahap Penyusunan Sistem yang Dirancang

Perancangan sistem start engine mobil menggunakan fingerprint ini berfungsi untuk menghidupkan mesin kendaraan secara otomatis dengan menggunakan sidik jari pengguna yang sudah didaftarkan dan memiliki indikator LED serta alarm. Perancangan sistem ini menggunakan modul pendeteksi sidik jari untuk membaca dan memberikan input data pada modul pemroses. Modul pemroses dapat memproses data yang diterima dan dapat mengaktifkan modul otomatis starter sehingga mesin mobil dapat dihidupkan secara otomatis. Sistem juga memiliki alarm yang diaktifkan oleh modul pemroses bila ada pengguna yang tidak dikenal mencoba untuk menghidupkan mesin mobil sebanyak tigakali berturut-turut. Perancangan sistem start engine mobil menggunakan fingerprint memiliki diagram blok yang dapat dilihat pada Gambar 3.

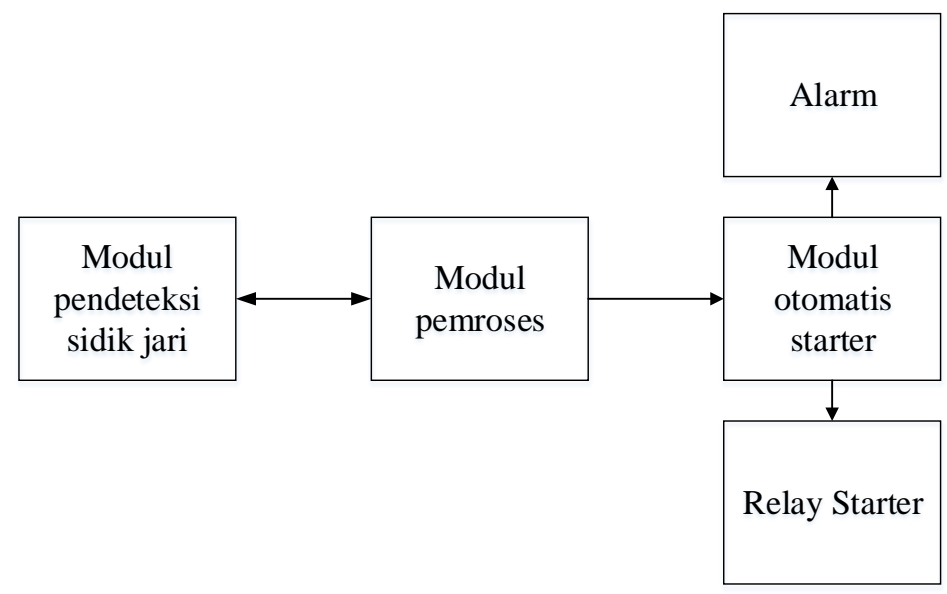

- Gambar 3. Diagram Blok Keseluruhan Sistem

Sidik jari adalah kulit pada telapak tangan dan kaki yang tertutupi garis-garis halus yang menonjol keluar satu sama lain dan dipisahkan oleh celah atau alur yang membentuk pola tertentu. Sidik jari setiap manusia pasti berbeda dan tidak ada sidik jari yang sama meskipun dalam satu tangan. Pola sidik jari selalu ada dalam setiap telapak tangan dan telapak kaki manusia. Pola sidik jari juga bersifat permanen yang artinya, dari lahir hingga dewasa sampai meninggal dunia pola itu tidak akan berubah. Setiap jari manusia memiliki pola sidik jari yang berbeda-beda. Menurut ilmu yang mempelajari tentang sidik jari (Dermatoglyphics) ada tiga pola dasar tentang sidik jari, yaitu pola Arch, pola Loop, dan pola Whorl. Selain itu hanya variasi dari kombinasi ketiga pola ini[4]. Pola sidik jari dapat dilihat pada Gambar 4. 


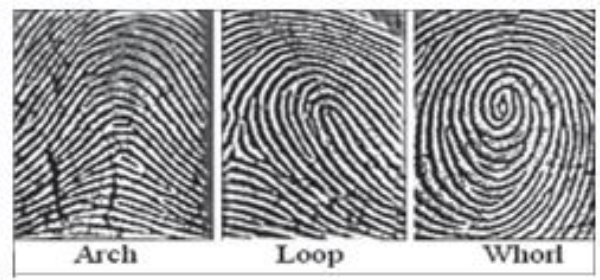

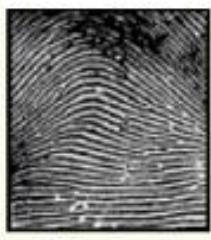

Plain Arch

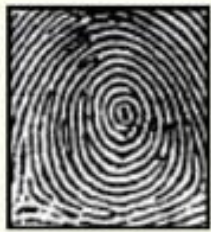

Plain Whorl

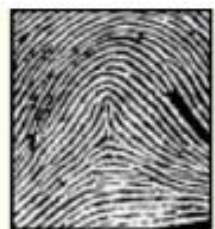

Tented Arch

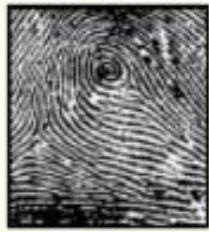

Central Pocket

Loop

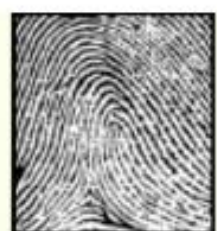

Ulnar Loop

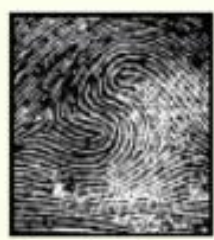

Double Loop

Whorl

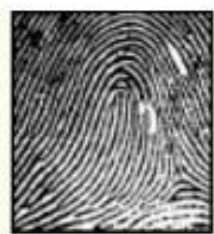

Radial Loop

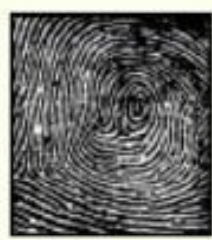

Accidental

Whorl

- Gambar 4. Pola Sidik Jari

Para ahli tertarik mempelajari tentang sidik jari karena setiap orang memiliki sidik jari yang berbeda, sidik jari bersifat permanen dan tidak bisa dipalsukan. Selain itu sidik jari mudah diklasifikasikan dan bisa diintegrasikan dengan teknologi serta dapat disimpan dalam data base.

Sensor sidik jari merupakan sebuah alat yang mampu membaca pola sidik jari. Pola sidik jari dapat dibedakan menjadi tiga jenis, yaitu whorl pattern, loop pattern, dan arch pattern. Berdasarkan pola-pola ini maka sidik jari dapat dibedakan secara umum. Namun tidak semua sensor sidik jari mampu membedakan setiap sidik jari yang ada hanya dengan sidik jari dalam membedakan setiap sidik jari yang ada. Metode pembacaan sidik jari antara lain metode optis, metode kapasitan, dan metode thermal.

Metode optis merupakan metode yang menggunakan cahaya untuk merekam pola sidik jari. Sensor sidik jari yang menggunakan metode optis memiliki tempat untuk meletakkan sidik jari yang disebut scan area dan tepat di bawah scan area terdapat pemancar cahaya yang menerangi permukaan scan area. Hasil pemantulan cahaya tersebut ditangkap oleh alat penerima yang selanjutnya menyimpan gambar sidik jari tersebut ke dalam memori. Cara kerja metode pembacaan sidik jari secara optis dapat dilihat pada Gambar 5A.

Kelemahan metode optis yaitu hasil scanning sangat tergantung dari kualitas sidik jari. Jika kualitas sidik jari tidak sempurna, rusak, atau sedang mengalami luka, maka kualitas hasil scanning jadi tidak maksimal. menggunakan ketiga pola tersebut. Terdapat beberapa metode yang digunakan oleh sensor Berbeda dengan metode optis, metode kapasitan merupakan metode yang menggunakan kapasitor dalam pembentukan citra sidik jari. Scan area berfungsi sebagai lempeng kapasitor, dan kulit ujung jari berfungsi sebagai lempeng kapasitor lainnya. Adanya ridge dan valley pada sidik jari akan membentuk pola sidik jari. Pembacaan sidik jari secara kapasitan dapat dilihat pada Gambar 5B Pada metode thermal, metode yang digunakan dengan cara menggosokan ujung jari pada scan area. Perbedaan suhu antara ridge dan valley pada sidik jari akan mebentuk pola sidik jari. Pembacaan sidik jari secara thermal dapat dilihat pada Gambar 5C. 
A.
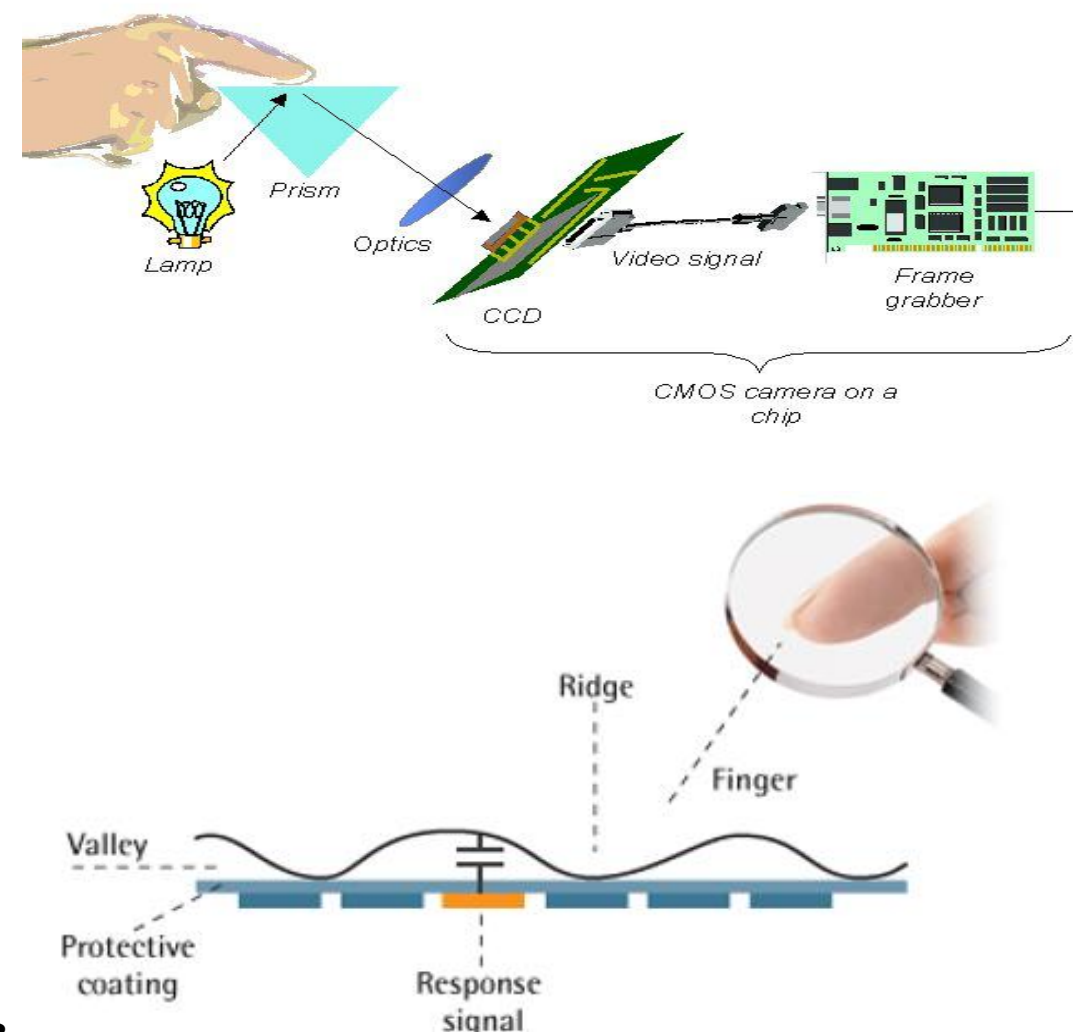

B.

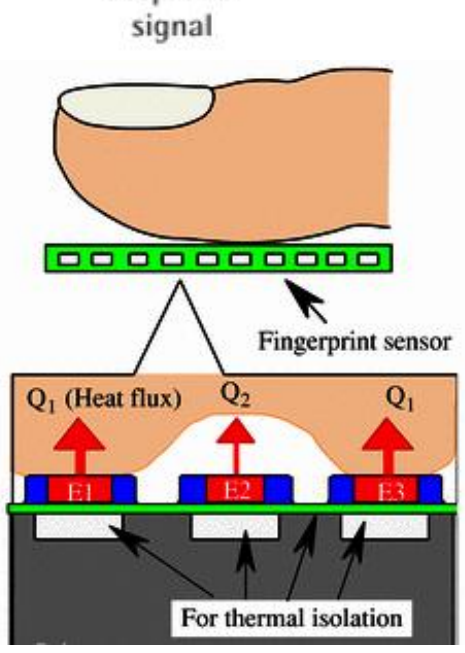

- Gambar 5. A. Pembacaan Sidik Jari Secara Optis

B. Pembacaan Sidik Jari Secara kapasitan

C. Pembacaan Sidik Jari Secara Thermal

\section{REALISASI RANCANGAN}

Realisasi rancangan subsistem pada sistem start engine menggunakan fingerprint meliputi beberapa modul, yaitu :

1. Realisasi modul registrasi

2. Realisasi modul otomatis starter,

3. Realisasi modul program security.

Realisasi modul registrasi memerlukan sebuah perangkat Personal Computer (PC) untuk melihat tampilan pada layar. Selain memerlukan PC pada realisasi modul registrasi juga memerlukan mikrokontroler, dan sebuah sensor sidik jari. Pada layar PC dapat menampilkan cara mendaftarkan sidik jari pengguna dan dapat menampilkan hasil dari pendaftaran sidik jari pengguna yang sudah berhasil disimpan atau tidak berhasil disimpan.

Sensor sidik jari dihubungkan dengan mikrokontroler melalui port digital input/output dan port power output. Pada port digital input/output mikrokontroller, digunakan pin 2 dan pin 3 yang berfungsi sebagai komunikasi secara serial mikrokontroler dengan sensor sidik jari. Selain menggunakan port input/output pada mikrokontroler digunakan juga port power output yang berfungsi untuk mengaktifkan sensor sidik jari melalui 
pin 5 VCC dan pin GND. Setelah menghubungkan sensor sidik jari dengan mikrokontroler selanjutnya board mikrokontroler dihubungkan dengan PC secara serial menggunakan port USB. Tampilan fisik dari modul registrasi dapat dilihat pada Gambar 6.

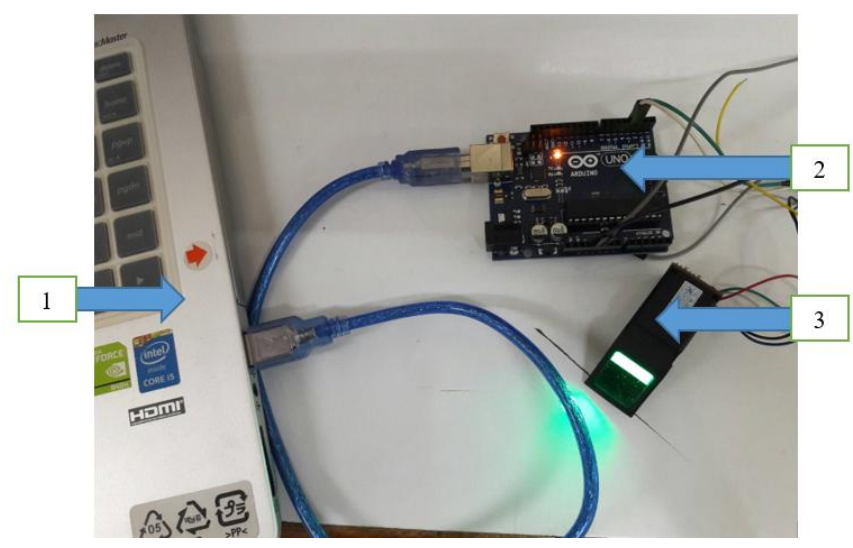

- Gambar 6. Tampilan Fisik Modul Registrasi

Keterangan Gambar :

1. Personal Computer

2. Mikrokontroler

3. Sensor sidik jari

Pengguna yang mendaftarkan sidik jarinya diminta memasukkan sidik jarinya sebanyak dua kali. Hal ini dikarenakan modul pendeteksi sidik jari akan mencocokkan sidik jari pertama dengan sidik jari kedua pengguna yang didaftarkan. Selain itu, setiap pengguna yang ingin didaftarkan harus mendaftarkan sidik jari tangan kanan dan tangan kiri untuk disimpan pada sistem ini. Hal ini dikarenakan bila sidik jari tangan kanan pengguna mengalami luka maka pengguna dapat menggunakan sidik jari tangan kirinya untuk tetap dapat menghidupkan mesin mobil. Diagram alir modul registrasi dapat dilihat pada Gambar 8.

Modul registrasi ini digunakan untuk mendaftarkan dan menyimpan sidik jari pengguna yang didaftarkan pada sistem. PC yang terhubung dengan mikrokontroler dan sensor sidik jari, layar pada PC dapat menampilkan tampilan pada layar untuk menyimpan ID pengguna yang didaftarkan. Pertama-tama pengguna yang mendaftarkan sidik jarinya harus memberikan input sidik jarinya di atas sensor sidik jari. Layar pada PC kemudian menampilkan pemberitahuan untuk mengangkat jari pengguna dari atas sensor sidik jari. Setelah pengguna mengangkat jari dari sensor sidik jari, pengguna kemudian diminta kembali untuk meletakkan sidik jari yang sama di atas sensor sidik jari. Bila sidik jari pengguna yang didaftarkan sama dengan sidik jari sebelumnya maka sidik jari akan tersimpan. Bila sidik jari yang didaftarkan berbeda dengan sidik jari sebelumnya maka sidik jari tidak dapat disimpan dan harus mengulang proses pendaftaran sidik jari dari awal.

Modul otomatis starter ini digunakan untuk menghidupkan mesin kendaraan secara otomatis. Pada saat sidik jari pengguna yang sudah didaftarkan dan berhasil disimpan maka modul otomatis starter dapat aktif sehingga mesin mobil dapat dihidupkan secara otomatis. Modul otomatis starter ini menggunakan beberapa komponen elektronika yaitu resistor, transistor, dioda dan relay. Schematic rangkaian dan bentuk fisik modul otomatis starter dapat dilihat pada Gambar 7. 


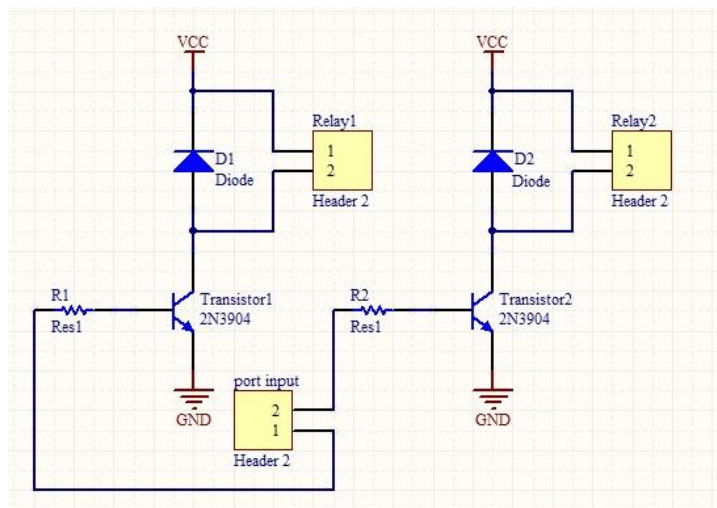

A.

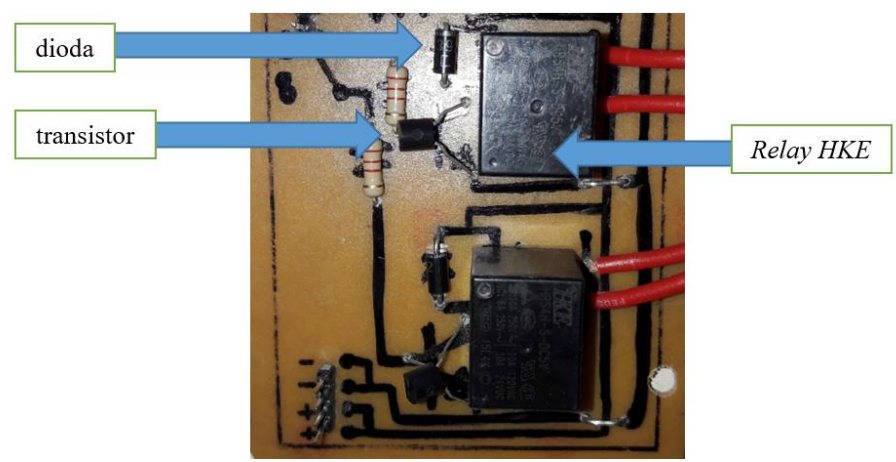

B.

- Gambar 7. A. Schematic Rangkaian Modul Otomatis Starter

B. Bentuk fisik Modul Otomatis Starter

Modul otomatis starter ini digunakan transistor untuk mengaktifkan relay yang membutuhkan tegangan $5 \mathrm{~V}_{\mathrm{DC}}$. Hal ini dikarenakan output yang dihasilkan dari mikrokontroller sebesar $3.3 \mathrm{~V}_{\mathrm{DC}}$. Selain menggunakan transistor dan relay, Modul otomatis starter ini juga menggunakan dioda untuk menjaga adanya arus balik dari relay yang dapat membahayakan mikrokontroler dan sensor sidik jari. Berdasarkan Gambar 24 dan Gambar 25, pada saat modul otomatis starter mendapatkan input tegangan dari mikrokontroller, maka transistor dan relay aktif sehingga mesin mobil dapat dihidupkan secara otomatis. Sebaliknya, bila modul otomatis starter tidak mendapatkan input tegangan dari mikrokontroller, maka transistor dan relay tidak dapat aktif sehingga mesin mobil juga tidak dapat dihidupkan secara otomatis. Pada modul otomatis starter juga digunakan dioda untuk melindungi mikrokontroller dari adanya arus balik yang terjadi akibat induksi dari relay yang aktif. Dengan menggunkan rangkaian ini mikrokontoler akan aman dari adanya arus berlebih dari relay yang berfungsi untuk mengaktifkan mesin mobil secara otomatis.

Pada realisasi modul otomatis starter ini juga sedikit memodifikasi sistem kelistrikan pada kontak mobil. Mobil yang masih menggunakan sistem konvensional untuk menghidupkan mesin mobil perlu memodifikasi sedikit sistem kelistrikannya. Schematic sistem kelistrikan pada kontak mobil untuk menghidupkan mesin dapat dilihat pada Gambar 8 . 


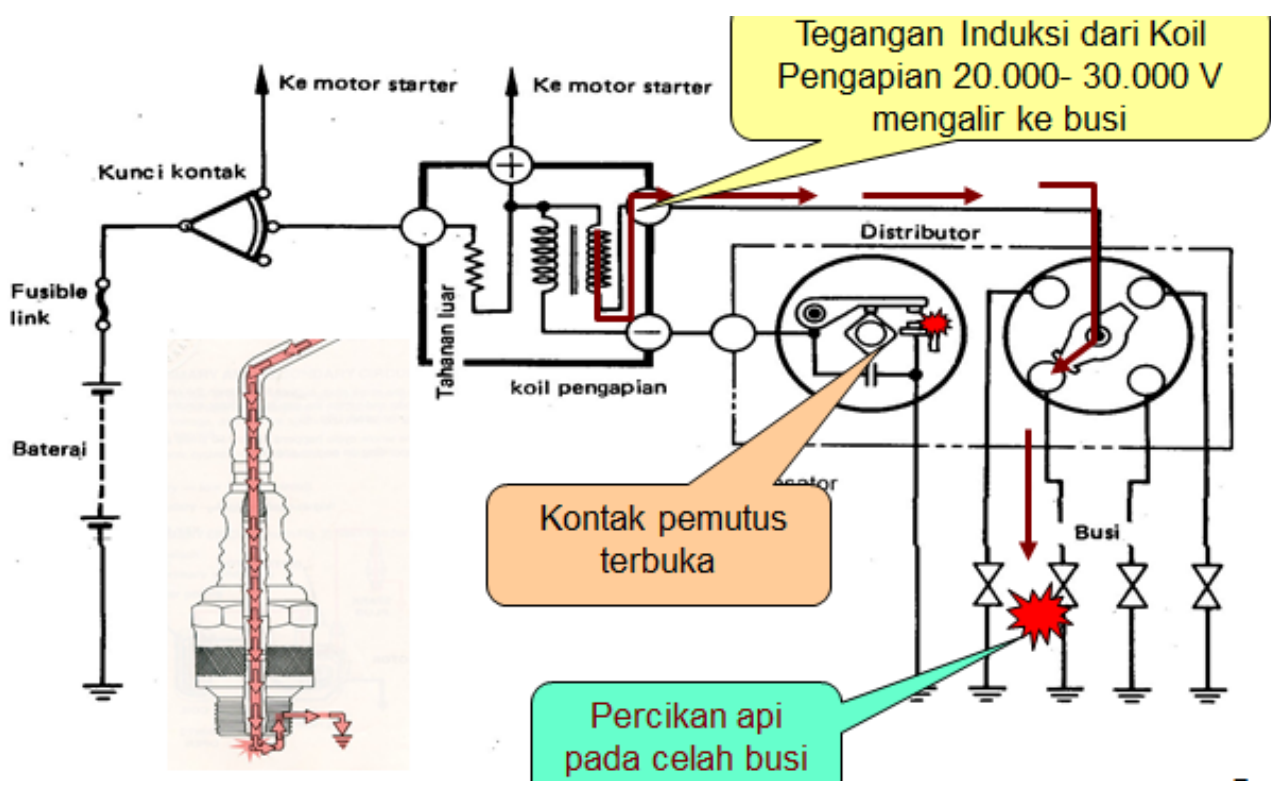

- Gambar 8. Schematic Sistem Kelistrikan Pada Kontak Mobil
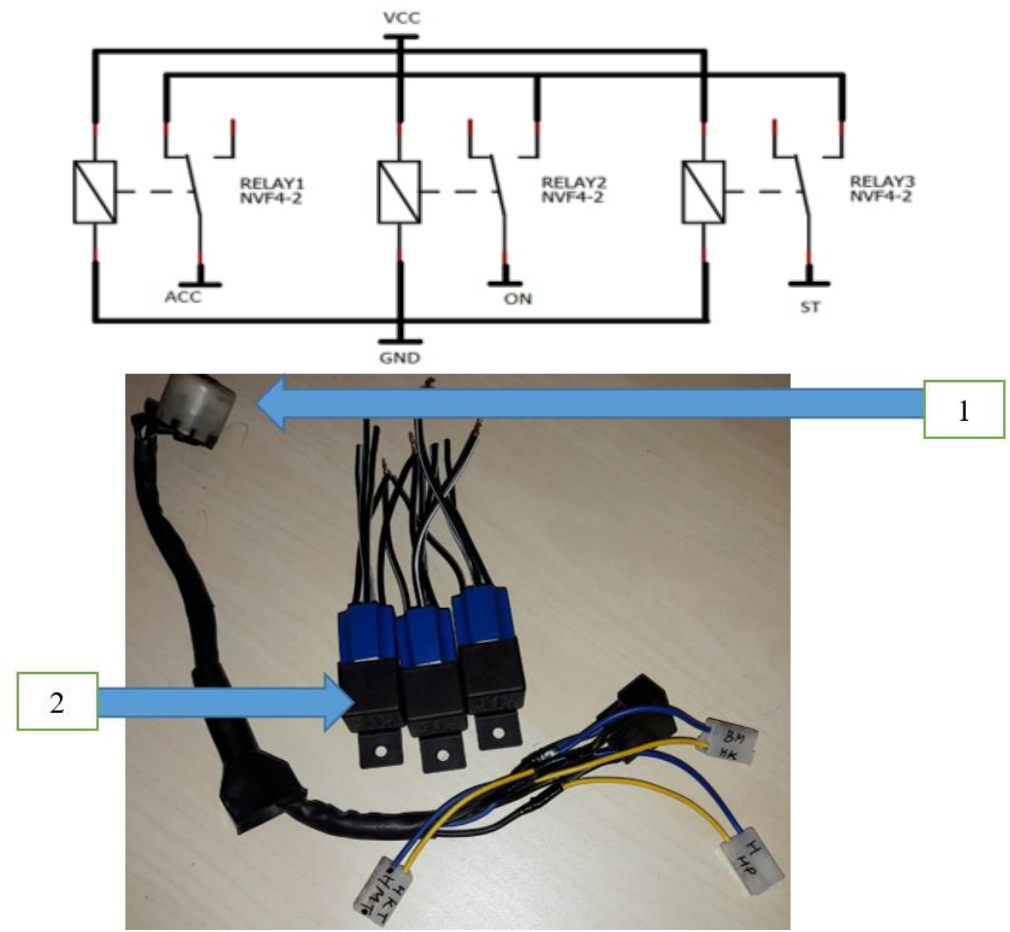

- Gambar 9. Bentuk Fisik Modifikasi Sistem Kelistrikan Pada Kontak Mobil.

\section{Keterangan Gambar :}

1. Rumah kunci kontak mobil

2. Modifikasi relay starter

Sistem kelistrikan mobil yang masih menggunakan cara konvensional saat menghidupkan mesin mobil dapat dimodifikasi menggunakan relay Bosch. Relay ini dihubungkan sesuai dengan kondisi dan posisi setiap terminal pada sistem kelistrikan kontak mobil. Relay ini yang digunakan untuk menggantikan sistem konvensional menjadi sistem elektrikal sehingga mesin mobil dapat diakfifkan secara otomatis. Posisi setiap terminal pada kontak mobil dapat dilihat pada Tabel 1. 
- Tabel 1. Posisi Setiap Terminal Pada Kontak Mobil

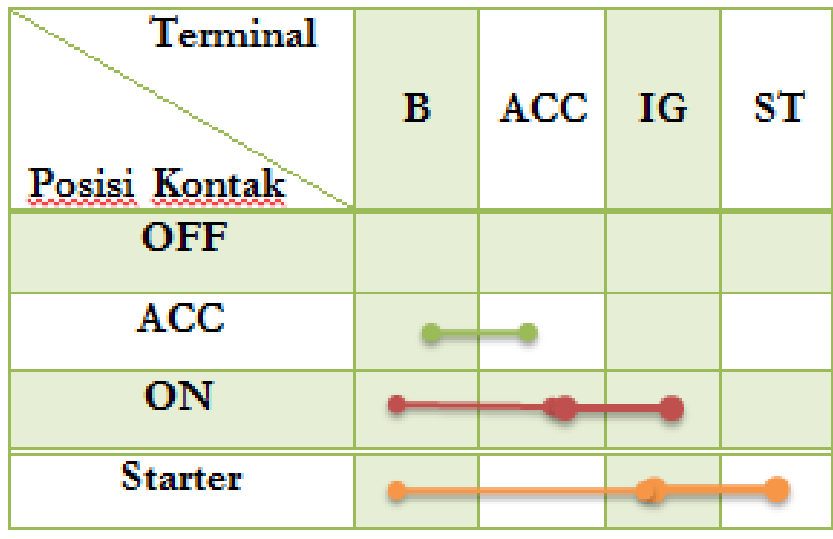

Pada posisi kontak mobil OFF semua terminal tidak ada yang saling terhubung sehingga pada posisi kontak mobil OFF mobil tidak dapat menghidupkan apapun. Pada saat kunci kontak mobil diposisi ACC maka terminal yang saling terhubung yaitu terminal B dan terminal ACC sehingga, pada posisi kontak mobil ACC maka mobil hanya dapat menghidupkan accessories pada mobil seperti radio/tape, cigarate soket, lampu mobil dan lampu kabin. Pada posisi kontak mobil ON maka terminal yang saling terhubung yaitu

terminal B terminal ACC dan terminal IG sehingga pada saat mobil di posisi ON maka mesin mobil siap untuk dihidupkan. Pada saat posisi kontak mobil distarter maka terminal B terminal IG dan terminal ST saling terhubung sehingga mesin mobil dapat menyala.

Pada posisi kontak starter terminal ACC tidak terhubung degan terminal lainnya dikarenakan untuk melindungi perangkat accessories pada mobil dari adanya lonjakan arus yang terjadi saat mesin mobil dihidupkan. Dengan mengetahui cara kerja dan terminal yang saling terhubung disetiap posisinya maka dapat dimodifikasinya dengan menggunakan relay agar mesin mobil dapat dihidupkan tanpa menggunakan kunci kontak. Schematic rangkaian dan bentuk fisik modifikasi sistem kelistrikan pada kontak mobil dapat dilihat pada Gambar 8.

Dengan memodifikasi menggunakan relay maka untuk menghidupkan mesin mobil tidak memerlukan cara konvensional lagi. Mesin mobil dapat diaktifkan secara otomatis dengan menghubungkan relay ke modul otomatis starter, sehingga dengan hanya memberikan input sidik jari yang sudah terdaftar maka mesin mobil dapat diaktifkan tanpa menggunakan anak kunci.

Realisasi modul program security dilakukan dengan membuat program pada mikrokontroler yang berfungsi sebagai sistem keamanan. Program ini bertujuan agar sistem dapat mendeteksi dan mengenali sidik jari pengguna yang dapat menghidupkan mesin mobil secara otomatis. Program ini juga bertujuan agar dapat mengaktifkan modul otomatis starter sehingga mesin mobil dapat dihidupkan secara otomatis. Selain itu, program ini juga dapat mengaktifkan LED, relay dan alarm sebagai indikator bila ada sidik jari pengguna yang tidak dikenal mencoba untuk menghidupkan mesin mobil.

Modul pendeteksi sidik jari dihubungkan dengan modul pemroses dengan cara menghubungkan pin VCC dan pin GND dari modul pendeteksi sidik jari ke-port power output dari modul pemroses pada pin 5 VCC dan pin GND. Selain menghubungkan pin VCC dan pin GND pada modul pendeteksi sidik jari, pin data in dan pin data out juga dihubungkan dengan modul pemroses menggunakan port digital in/out pada pin 2 dan pin 3 . Kedua pin ini digunakan untuk komunikasi serial modul pendeteksi sidik jari dengan modul pemroses. Setelah modul pendeteksi sidik jari selesai dihubungkan dengan modul pemroses maka selanjutnya menggabungkan modul otomatis starter dengan modul pemroses. 

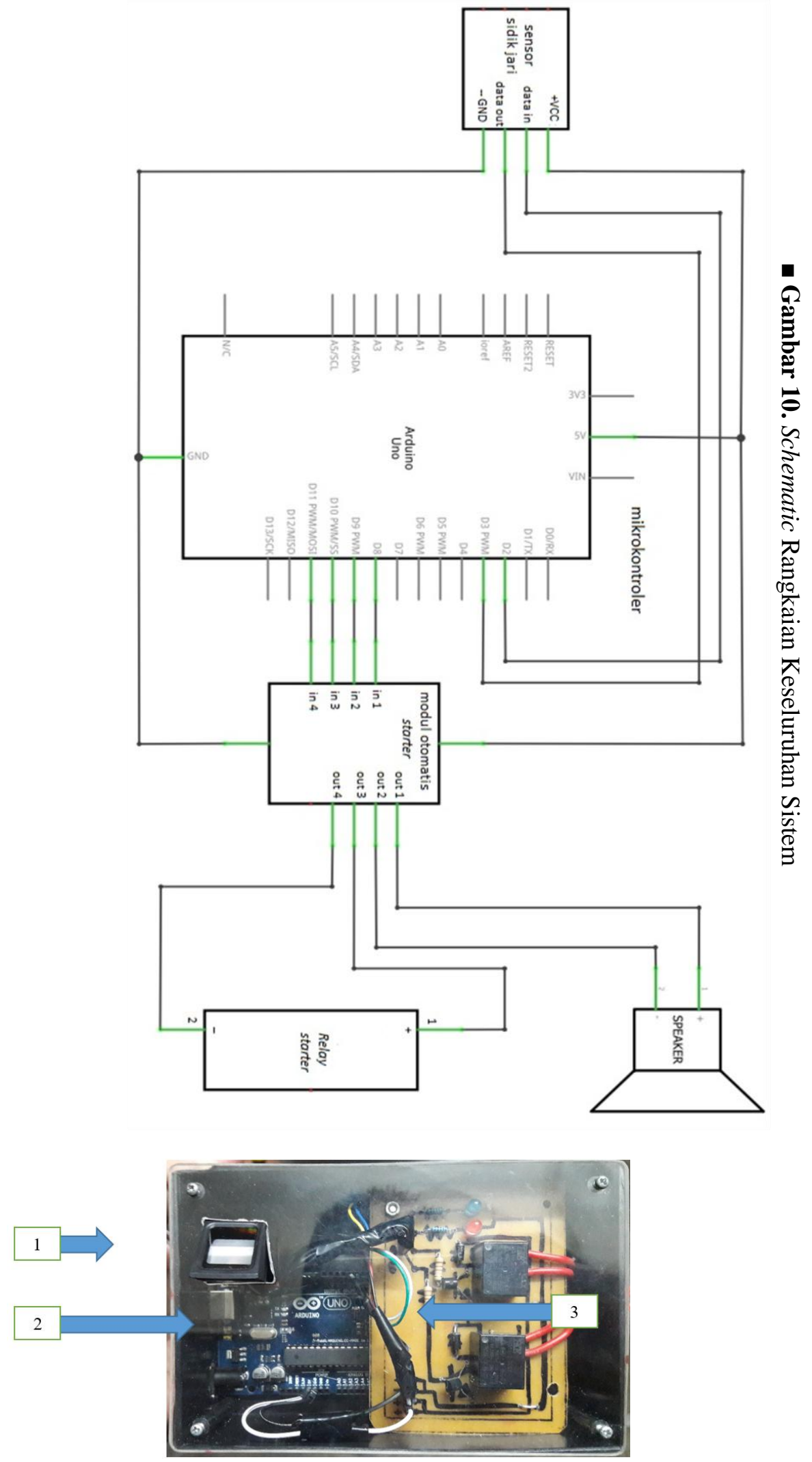

- Gambar 11. Bentuk Fisik Keseluruhan Sistem

Keterangan Gambar:

1. Sensor sidik jari

2. Mikrokontroler

3. Modul Otomatis Starter 


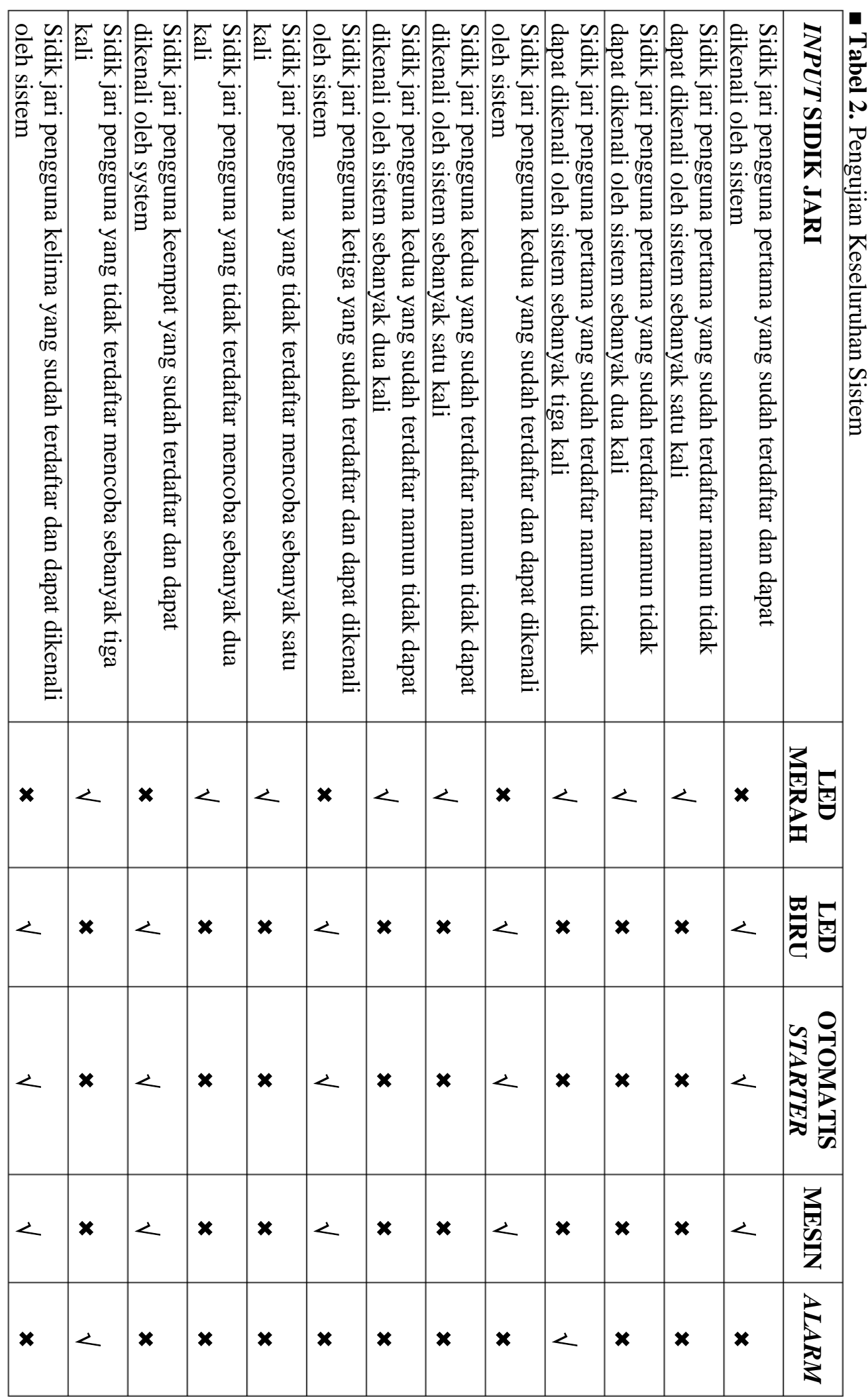

Pada dasarnya realisasi rancangan keseluruhan sistem ini adalah ketika pengguna mobil yang sidik jarinya sudah terdaftar digunakan untuk menghidupkan mesin mobil, maka mesin mobil dapat dihidupkan secara otomatis dan sistem dapat menampilkan indikator LED biru yang menyala. Sebaliknya, ketika pengguna mobil yang sidik jarinya tidak terdaftar digunakan untuk menghidupkan mesin mobil, maka mesin mobil tidak dapat dihidupkan secara otomatis melainkan sistem dapat menampilkan indikator LED merah yang menyala. Namun bila pengguna mobil yang sidik jarinya tidak terdaftar digunakan untuk mencoba menghidupkan mesin mobil sebanyak tiga kali berturut-turut, maka sistem dapat mengaktifkan alarm mobil dan indikator LED merah yang menyala berkedip serta mesin mobil tetap tidak dapat diaktifkan secara otomatis. Dengan sistem seperti ini pengguna mobil dapat dengan mudah dalam menghidupkan mesin mobil secara otomatis dan mobil tetap memiliki sistem keamanan. 


\section{HASIL PENGUJIAN DAN ANALISIS}

Pengujian keseluruhan sistem ini bertujuan untuk mengetahui kemampuan sistem yang dibuat dapat bekerja dengan baik atau tidak. Pengujian keseluruhan sistem dilakukan dengan cara langsung menerapkannya pada mobil Toyota Crown Deluxe 2600cc tahun 1979. Pada pengujian ini, pengguna dapat menghidupkan mesin mobil secara otomatis dengan menggunakan sidik jari pengguna yang sudah berhasil didaftarkan. Sedangkan, pengguna yang sidik jarinya tidak terdaftar mencoba mengaktifkan mesin mobil sebanyak tiga kali berturut-turut maka alarm dapat berbunyi. Berikut tabel pengujian akan ditunjukkan pada Tabel 2. Berdasarkan hasil pengujian pada Tabel 2, mesin mobil dapat di aktifkan oleh pengguna yang sidik jarinya sudah berhasil didaftarkan saja. Sistem ini juga dapat mengaktifkan alarm jika pengguna yang tidak terdaftar mencoba mengaktifkan mesin mobil sebanyak tiga kali berturut-turut. Pengujian ini dianggap berhasil karena pada setiap modul berhasil melakukan tugasnya sesuai dengan yang dirancang. Dengan demikian dapat disimpulkan bahwa keseluruhan sistem bekerja dengan baik.

\section{KESIMPULAN}

Berdasarkan alat yang dirancang pada sistem start engine mobil menggunakan fingerprint tampak Sistem yang dirancang secara otomatis dapat menghidupkan mesin mobil hanya dengan menggunakan sidik jari pengguna yang sudah didaftarkan. Sistem yang dirancang dapat mengaktifkan indikator alarm bila ada pengguna yang tidak dikenali oleh sistem mencoba menghidupkan mesin mobil. Modul program security dapat mengaktifkan LED, relay dan alarm sesuai dengan input sidik jari yang diberikan pada sensor sidik jari. Modul otomatis starter dapat menghidupkan mesin mobil secara otomatis hanya dengan menggunakan sidik jari pengguna yang sudah terdaftar saja.

\section{DAFTAR PUSTAKA}

[1] Marta Dinata, Yuwono, Arduino Itu Mudah + CD. Jakarta: Indonesia, 2015.

[2] Muis, Saluduin, Teknologi Nano Jilid 2: Dalam Pembuatan Sensor Layar Sentuh. Indonesia: Surabaya, 2013. 